V Seminário Anual Científico e Tecnológico | Bio-Manguinhos

\title{
BIO 01 - Avaliação de suplementos nutricionais no cultivo de células CHO recombinantes em suspensão
}

Ethiene da Silva Corrêa Rocha ${ }^{1 *}$; Tiago Pereira dos Santos ${ }^{1}$; Rodrigo Coelho Ventura Pinto $^{1}$; Álvaro Paiva Braga de Sousa ${ }^{1}$.

1 Bio-Manguinhos / Fiocruz.

\section{Introdução:}

Com o avanço das técnicas de biologia molecular, os cultivos celulares passaram a ser uma importante plataforma para a produção de proteínas recombinantes com fins terapêuticos, como os biofármacos. A Eritropoetina humama recombinante (EPOhr) obtida por processos biotecnológicos é um biofármaco utilizado principalmente no tratamento da anemia associada à insuficiência renal crônica. A EPOhr é produzida em sistemas de cultivo de células animais, utilizando principalmente a linhagem celular CHO (Chinese Hamster Ovary). Estratégias de suplementação do meio de cultivo com componentes chaves para o metabolismo das células estão associadas ao incremento de taxas específicas de crescimento e síntese de produto, além de garantir atributos necessários para a qualidade do produto. Os suplementos estudados foram avaliados a partir de planejamento experimental fornecendo ferramentas que favoreçam a compreensão dos dados experimentais.

\section{Objetivo:}

Comparar a performance dos cultivos de células $\mathrm{CHO}$ expressando EPOhr suplementados com diferentes formulações nutricionais utilizando suplementos nutricionais (Cell Boost) e, identificar quais Cell Boost poderão contribuir na obtenção de maior concentração de células viáveis/mL e de EPOhr produzida.

\section{Metodologia:}

Foram estudados seis suplementos nutricionais comerciais adicionados a $10 \%(\mathrm{v} / \mathrm{v})$ no primeiro dia de cultivo (dia zero) ao meio de cultivo base, SFM4CHO -Utility, observando a influência sobre a proliferação celular e a produção da EPOhr. Inicialmente, utilizando planejamento fatorial fracionado 26-2 foram identificados três suplementos que influenciaram positivamente os cultivos. Foi realizado o cálculo da integral de células viáveis (ICV) e, a dosagem de EPOhr $(\mu \mathrm{g} / \mathrm{mL})$ por ELISA. Os dados experimentais foram 
analisados empregando o programa Statistica. O planejamento fatorial completo não propôs um modelo matemático esperado, então realizou-se um delineamento composto central rotacional (DCCR) que possibilitou melhor avaliação dos efeitos dos suplementos. Os cultivos celulares foram realizados em frascos $\mathrm{T} 25 \mathrm{~cm} 2$, mantidos a $37^{\circ} \mathrm{C}$, sem $\mathrm{CO} 2$.

\section{Resultado:}

A combinação dos suplementos (CB2, CB4 e CB5) melhorou o desempenho do cultivo celular e alcançou maior concentração de EPOhr. A partir do delineamento experimental, foi possível identificar as concentrações ideais dos suplementos CB2 (37,5g/L) e CB5 $(12,5 \mathrm{~g} / \mathrm{L})$, que favoreceram o aumento da proliferação celular e da secreção da proteína EPOhr. A maior concentração foi de 3,27x107 células.dia/mL para a formulação (F11) no planejamento fatorial fracionado, e a maior concentração de EPOhr foi de 119,65 $\mu \mathrm{g} / \mathrm{mL}$ para a formulação (F2) no DCCR.

\section{Conclusão:}

A técnica de planejamento experimental atendeu satisfatoriamente ao processo de seleção dentre os seis suplementos estudados (CB1, CB2, CB3, CB4, CB5 e CB6), fornecendo ferramentas que favoreceram a compreensão dos dados experimentais. As técnicas estatísticas utilizadas permitiram quantificar os efeitos das variáveis de processo resultando em significativo aumento de $103,11 \%$ na integral de células viáveis e de 207,98\% na produção de EPOhr, selecionando, desta forma, os suplementos (CB2, CB4 e CB5).

Palavras-chave: Planejamento experimental; suplementos nutricionais; CHO 